\title{
ACL Injuries Identifiable for Pre-participation Imagiological Analysis: Risk Factors
}

\author{
Hélder Pereira $^{\mathrm{a}, \mathrm{b}, \mathrm{c}, \mathrm{d} *}$, Margarida Fernandes ${ }^{\mathrm{c}}$, Rogério Pereira $^{\mathrm{c}}$, Henrique Jones ${ }^{\mathrm{e}}$, J. C. Vasconcelos ${ }^{\mathrm{c}}$, J. M. Oliveira ${ }^{\mathrm{a}, \mathrm{b}, \mathrm{c}}$, \\ R. L. Reis ${ }^{\mathrm{a}, \mathrm{b}, \mathrm{c}}$, Volker Musahl $^{\mathrm{f}}$ and J. Espregueira-Mendes ${ }^{\mathrm{a}, \mathrm{b}, \mathrm{c}, \mathrm{d}}$ \\ a3B's Research Group - Biomaterials, Biodegradables and Biomimetics, Headquarters of the European Institute of \\ Excellence on Tissue Engineering and Regenerative Medicine, Univ. Minho, Guimarães, Taipas, Portugal \\ ${ }^{\mathrm{b}}$ ICVS/3B's - PT Government Associated Laboratory, Braga/Guimarães, Portugal \\ ${ }^{c}$ FIFA Medical Centre of Excellence, Clínica Espregueira-Mendes F.C. Porto Stadium, Porto, Portugal \\ ${ }^{\mathrm{d} O r t h o p e d i c ~ D e p a r t m e n t, ~ C e n t r o ~ H o s p i t a l a r ~ P o ́ v o a ~ d e ~ V a r z i m, ~ V i l a ~ d o ~ C o n d e, ~ P o r t u g a l ~}$ \\ ${ }^{e}$ Medical Department, Portuguese Football Federations and UEFA Medical Committee, Lisbon, Portugal \\ ${ }^{f}$ Department of Orthopaedic Surgery, University of Pittsburgh Medical Center, Pittsburgh, PA, USA
}

\begin{abstract}
Identification of pre-participation risk factors for noncontact anterior cruciate ligament (ACL) injuries has been attracting a great deal of interest in the sports medicine and traumatology communities. Appropriate methods that enable predicting which patients could benefit from preventive strategies are most welcome. This would enable athlete-specific training and conditioning or tailored equipment in order to develop appropriate strategies to reduce incidence of injury. In order to accomplish these goals, the ideal system should be able to assess both anatomic and functional features. Complementarily, the screening method must be cost-effective and suited for widespread application. Anatomic study protocol requiring only standard X rays could answer some of such demands. Dynamic MRI/CT evaluation and electronically assisted pivot-shift evaluation can be powerful tools providing complementary information. These upcoming insights, when validated and properly combined, envision changing pre-participation knee examination in the near future. Herein different methods (validated or under research) aiming to improve the capacity to identify persons/athletes with higher risk for ACL injury are overviewed.
\end{abstract}

\section{Introduction}

Knee ligament reconstruction surgery is currently a common practice worldwide. In particular, anterior cruciate ligament (ACL) injury remains among the most common causes of orthopedic surgery (Griffin et al. 2000; Chadwick et al. 2008). Considering surgical reconstruction of ACL alone, it is estimated that more than 100,000 procedures are performed annually in the USA (Owings and Kozak 1998; Griffin et al. 2000), thus representing yearly costs that exceed 0.5 billion dollars. Such prevalence states the importance of knee surgeons to define strategies for early diagnosis and prevention based in detection of risk factors. Any action able to contribute for reducing the incidence of this injury, besides the personal and athletic benefit, would probably have a significant social and economic impact (Chadwick et al. 2008).

*Email: heldermdpereira@gmail.com 
If it were possible to identify pre-participation athletes with increased risk of noncontact ACL injury based in a method suitable for widespread application, one could properly adjust their training methods.

Intensive research on ACL pathophysiology and surgery (anatomy, biology, physiopathology, and biomechanics) has been done, which contributed to important clinical improvements (e.g., graft selection, surgical techniques, tunnel placement, graft fixation, and rehabilitation protocols). Recently, new trends related to the biology of graft incorporation and "ligamentization" process have also improved the ability to prevent postoperative complications such as excessive graft elongation, pullout, or slippage (Menetrey et al. 2008).

Recognizing all the previous, it seems mandatory to put similar efforts focused on prevention strategies (Arendt and Brown 2012).

Athletes and general population have higher expectations concerning medical care. From the initial stand for prevention of arthritis following ACL rupture, nowadays people want to prevent injury by "working" in advance. Only if this is not possible, then the actual demand is complete repair of anatomy and functional recovery including highly demanding activities (Georgoulis et al. 2007; Tashman et al. 2007).

A group of ACL injury risk factors including neuromuscular, hormonal, genetic, cognitive, functional, and previous injury or a variety of extrinsic risk factors will be discussed separately (Sward et al. 2010; Smith et al. 2012a, b).

In the following sections, the identifiable risk factors for ACL rupture, with a particular emphasis in the morphologic/anatomic characteristics determined by clinical examination, conventional radiology or dynamic MRI/CT protocols, or technologically enhanced evaluation methods will be summarized.

\section{Manual Instrumented Devices}

Manual instrumented tests aim to enhance manual examination by providing more objective information which could be more easily transmitted and analyzed but still be suitable for use "in office."

However, most of such devices share some limitations with clinical examination such as: absence of bony landmarks, influenced by muscle guarding, or being operator dependent (Pereira et al. 2012).

Several arthrometers have been presented through time. The KT-1000 laximeter (Medmetric, San Diego, CA, USA) (Daniel et al. 1985) is probably the most commonly used and is still the reference instrument to which new devices have been tested (Robert et al. 2009). However, KT-1000 has been considered as operator dependent with significant false-negative results and questionable reproducibility (Jardin et al. 1999; Boyer et al. 2004). The KT-2000 Ligament Arthrometer (KT-2000; Medmetric Corp) uses the same method as the KT-1000, and the main difference concerns the data output which includes a graphic presentation representing the amount of tibial displacement correlated to the amount of applied force via an X-Y plotter (Myrer et al. 1996). Neither of them is suitable for rotatory laxity assessment.

Several devices are currently accessible (see Table 1).

However, none of these systems have proved to be more effective than clinical examination alone (Myrer et al. 1996) and share comparable limitations (intraclass correlation coefficient [ICC], 0.6). 
Table 1 Currently available manual instrumented devices

\begin{tabular}{ll}
\hline Device & References \\
\hline KT-1000 laximeter (Medmetric, San Diego, CA, USA) & Daniel et al. 1985 \\
\hline $\begin{array}{l}\text { KT-2000 laximeter (Medmetric, San Diego, CA, USA) } \\
\text { Stryker Knee Laxity Tester (Stryker, Kalamazoo, MI) }\end{array}$ & $\begin{array}{l}\text { Myrer et al. 1996 } \\
\text { Boniface et al. 1986, Highgenboten } \\
\text { et al. 1989 }\end{array}$ \\
\hline $\begin{array}{l}\text { Genucom Knee Analysis System (FARO Medical Technologies, Montreal, } \\
\text { Ontario Canada) }\end{array}$ & $\begin{array}{l}\text { Oliver and Coughlin 1987 } \\
\text { Kneelax 3 (Monitored Rehab Systems, Haarlem, The Netherlands) }\end{array}$ \\
\hline $\begin{array}{l}\text { Rolimeter (Aircast Europa, Neubeuern, Germany) } \\
\text { CA-4000 Electrogoniometer (OSI, Hayward, CA) }\end{array}$ & Benvenuti et al. 1998 \\
\hline
\end{tabular}

\section{iPad Application}

Methods for ACL injury prediction using clinic-based measurements and computer analyses that require only freely available public domain software have been envisioned (Myer et al. 2011).

Common electronic devices used in daily living such as the iPad (Apple Inc., Cupertino, CA, USA) by means of an adequate user-friendly application might enhance clinical analysis protocol in the near future. This could be true either for clinical testing or imaging study.

Manual examinations are influenced by surgeon's training and experience and currently rely in subjective impressions (Branch et al. 2010b). Pivot-shift test has been considered a better predictor of clinical outcomes than any other uniplanar maneuver (Katz and Fingeroth 1986; Citak et al. 2011). Nevertheless, the Lachman test has been considered as more sensitive (Prins 2006), and the limitations of the pivot-shift test, particularly in an awake patient, must be considered.

By providing a tool based in recorded motion images, it promises to improve objective assessment of clinical examination (Hoshino et al. 2013). The iPad app is currently under process of validation (PIVOT study; ISAKOS/OREF research grant) and it envisions creating new perspectives on detection of risk factors, preoperative evaluation, and clinical outcomes for patients. Possibly, in the future a similar computed analysis might combine clinical information with protocolled analysis of X-ray, CT, and MRI exams. Such electronic devices could ease the application of more complex analytic algorithms combining consideration of multiple factors but keeping it fast, easy to use, and affordable.

\section{Robotic Systems}

Robotic systems have promised to overcome bias inherent to manual force application by means of comprising mechanical methods to apply load or torque in a controlled mode (magnitude, direction, rate) (Lob et al. 2006; Park et al. 2008; Tsai et al. 2008; Robert et al. 2009; Woo and Fisher 2009; Branch et al. 2010a; Musahl et al. 2010; Citak et al. 2011; Mayr et al. 2011).

Using such approach, the Pittsburgh's study group has contributed great insights for understanding knee joint kinematics in multiple degree of freedom (Woo and Fisher 2009; Musahl et al. 2010).

The GNRB knee laxity testing device (Genurob, Montenay, France), provides an anteriorly directed force to the proximal tibia with the knee at $0^{\circ}$ rotation and $20^{\circ}$ flexion in a rigid leg support 
(Robert et al. 2009). The load is delivered gradually and the software compares side-to-side differences on the magnitude of anterior tibial translation but also a force-displacement curve whose slopes would reflect ACL elasticity.

It has been demonstrated in cadaveric hip-to-toe models that mechanized pivot-shift tests provide more reliable and consistent measurements of pivot-shift phenomenon (Musahl et al. 2010; Citak et al. 2011). Another device designed to assess knee rotation in non-injured knees has also been presented including its intra-tester, test-retest, and inter-tester reliability (Tsai et al. 2008). The authors concluded that such method presents acceptable reliability for clinical use.

Another study (Park et al. 2008) compared ten healthy men and ten healthy women with the knee at $60^{\circ}$ of flexion and established that women had increased external rotation laxity. Branch et al. (2010a) also reported gender-related outcomes with implications on detection of risk factors for ACL injury. Assuming the hypothesis that the opposite knee of patients with a previous ACL reconstruction presents biomechanical characteristics of greater risk for ACL rupture, the authors could demonstrate that knees with greater tibial internal rotation have higher risk for ACL injury when compared with healthy volunteers' (Balasch et al. 1999).

Another method (Mayr et al. 2011) was tested in the awake and non-anesthetized patient measuring anteroposterior translation and rotation of the knee joint. Tibial external/internal rotation was imposed with a torque of $2 \mathrm{Nm}$ on the footrest with the ankle locked in dorsiflexion. Anterior translation of the tibia in relation to the femur was measured in neutral position, internal and external rotation. Intra- and inter-rater reliability was validated in ten healthy volunteers. The authors concluded that the method enables to objectively discriminate isolated ACL rupture and ACL rupture combined with medial instability. The method demonstrated inter- and intra-observer reliability and reproducibility.

All these systems have not yet been included in routine clinical practice. They might be considered as somewhat expensive, time consuming, and/or requiring logistic demands which limit their "in office" application so far.

\section{Stress Radiography/Radiostereometry}

The combination of a stress device and radiography (stress radiography) has been proposed as a knee laxity measurement technique for ACL (Jonsson et al. 1992; Jardin et al. 1999; Isberg et al. 2006) and posterior cruciate ligament (PCL) assessment (Schulz et al. 2005; Jung et al. 2006).

The TELOS device (Telos GmbH, Laubscher, Hölstein, Switzerland) is the most common example of such a device. It permits to measure anterior and posterior drawer displacements controlling the magnitude of load transmission. The method considers the displacement of the midpoint between the tangents to the posterior contours of the tibial condyles drawn perpendicular to the tibial plateau and relative to the position of the corresponding midpoint between the two posterior aspects of the femoral condyles.

The reliability of TELOS device has been reported (Staubli et al. 1992).

These methods present the advantage over several others by considering bony landmarks to measure translation, thus avoiding issues related to soft-tissue artifact. However, no further information of knee joint soft-tissue, cartilage, or meniscus status is provided.

Radiostereometric analysis, originally presented by Selvik (1989), has been proposed as a method to enhance precision of translation measurement of the knee joint by stress radiography. This started as an invasive method that relies on implantation of tantalum beads and has high accuracy (within 
$0.1 \mathrm{~mm}$ ), which has also been proposed to assess migration of arthroplasty components throughout time.

There are reports stating the advantage of TELOS method over KT-1000 (Jardin et al. 1999), but limitations have been recognized even combining radiostereometric analysis based on the absence of a stress device that can produce reliable joint translation (Sorensen et al. 2011).

\section{Radiographic Assessment of Bone Morphology Risk Factors}

Morphologic characteristics identified in conventional X-ray protocols can provide an inexpensive, effective, and feasible tool to identify individuals in higher risk for ACL lesion. Standard radiological evaluation should include: (i) full-leg standing anteroposterior view (mechanical axes), (ii) standing anteroposterior and schuss view (assessment of notch morphology, evaluation of arthritic changes), (iii) standing lateral view in full extension and $30^{\circ}$ of flexion (tibial slope), and (iv) skyline view $\left(30^{\circ}\right.$ or $45^{\circ}$ of flexion) to evaluate patellofemoral articulation. The radiological protocols are a valuable, low-cost, accessible tool which helps gathering varied and fundamental information concerning bone morphology.

Femoral notch characteristics and tibial plateau slope and/or depth have been proposed as morphologic risk factors possible to identify from standard X-ray evaluation (Vyas et al. 2011; Smith et al. 2012b; Wordeman et al. 2012). Females are more likely than males to have a narrow A-shaped intercondylar notch which has been associated to gender-specific risk factor (Sutton and Bullock 2013). However, notch width index has not been considered a feasible method (Vyas et al. 2011).

There has been growing interest on study of tibial morphology by lateral X-ray or MRI (Wordeman et al. 2012). Dejour and Bonnin used lateral radiographs to demonstrate a mean $6 \mathrm{~mm}$ increase in anterior tibial translation (ATT) for each $10^{\circ}$ increase in posterior tibial slope in ACL-deficient patients and healthy controls (Dejour and Bonnin 1994).

A recent meta-analysis proposed to assess in vivo studies reporting tibial plateau slope as a risk factor for anterior cruciate ligament (ACL) injury (Wordeman et al. 2012). Most radiographic studies reporting medial tibial plateau slope (MTPS) demonstrated significant differences between controls and ACL-injured groups (Wordeman et al. 2012). Lateral tibial plateau slope (LTPS) was reported to be significantly greater in ACL-injured. It has been recognized that characterizing the tibial plateau surface with a single slope measurement represents an insufficient approximation of its threedimensionality, and the biomechanical impact of the tibial slope likely is more complex than previously appreciated (Feucht et al. 2013). Reported tibial slope values for control groups vary greatly between studies (Wordeman et al. 2012). A recent study proposed that the correlation between anteroposterior length of the external condyle and anteroposterior length of tibial plateau had stronger association to risk for ACL rupture (Fig. 1) (Pereira et al. 2013).

The clinical utility of imaging-based measurement methods for the determination of ACL injury risk requires more reliable techniques capable to demonstrate and preserve consistency between studies.

\section{Morphologic and Functional MRI Assessment: PKTD ${ }^{\circledR}$}

It has been proposed that a narrow intercondylar notch assessed by intercondylar notch width index on MRI may increase the risk of ACL injury, but the data are somewhat conflicting (Alizadeh and 


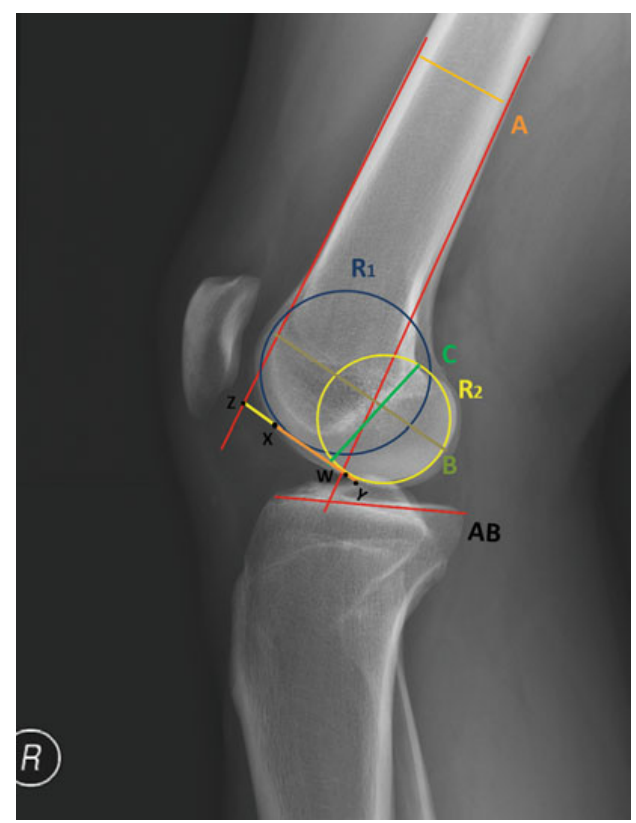

Fig. 1 Lateral X-ray view analysis: width of the femoral shaft $(E)$, anteroposterior length of the external condyle $(C)$, the proximal-distal height of external condyle $(D)$. Two perfect circles were created to adapt to the greater extent of anterior and posterior contour of lateral condyle and their radius considered ( $R 1$ and $R 2$, respectively). A tangent to both circles is drawn and the points where it intersects circle $1(x)$ and circle $2(y)$ are considered. The points where this straight line intersects the line of anterior $(z)$ and posterior $(w)$ femoral cortex lines are also drawn

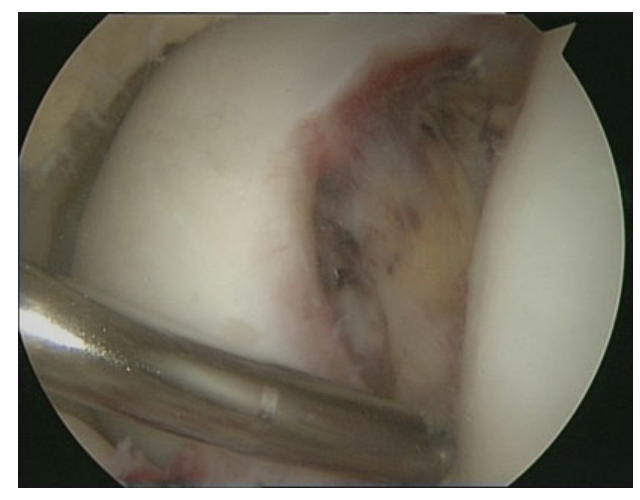

Fig. 2 Arthroscopic view of a type A intercondylar notch

Kiavash 2008). Females are more likely than males to have a narrow A-shaped intercondylar notch, and special surgical considerations are required in such cases (Fig. 2) (Sutton and Bullock 2013). Intercondylar notch stenosis and larger inner angle of lateral condyle of the femur are risk factors for 
ACL rupture by increasing the risk of ACL impingement in female athletes measured on coronal MR images (Miljko et al. 2012). The intercondylar notch dimensions were found to be smaller in the ACL-injured subjects, potentially putting the ACL at risk of impingement, and intercondylar notch volume was correlated to ACL volume $(r=0.58)$. Discriminant analysis showed that the notch width at the inlet could be a predictor of ACL injury (Simon et al. 2010). Enhanced height of the intercondylar notch and lesser value of the notch shape index were associated with rupture of the ACL in males but not in females (Stijak et al. 2012). It has been recently concluded that type A femoral notch appears to be a risk factor for ACL injury, whereas a reduced notch index has no significant correlation to ACL injury (Al-Saeed et al. 2013).

Proximal tibia morphologic study by MRI has generated increased interest through time (Table 2).

When compared with normal men, men with ACL tears had deeper medial and lateral tibial plateaus, as well as an increased posterior slope of the lateral tibial plateau (Bisson and GurskeDePerio 2010). Women with shallower medial tibial plateau depth and men with steeper lateral tibial

Table 2 Studies assessing tibial slope by MRI imaging as risk factor for ACL injury

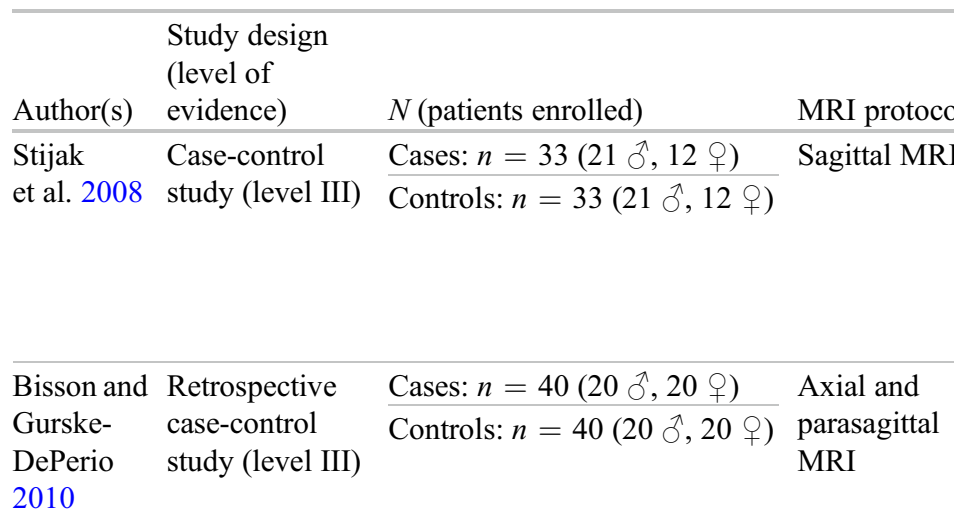

Conclusions

The greater tibial slope of the lateral tibial plateau may be the factor that leads to the injury of the anterior cruciate ligament. The tibial slope of the medial and lateral condyles should be compared separately

Women's knees presented proportionally deeper medial and lateral femoral condyles, as well as deeper medial tibial plateaus. Men with ACL tears had deeper medial and lateral tibial plateaus, as well as an increased posterior slope of the lateral tibial plateau comparing to controls

Hashemi Case-control Cases: $n=49(22 \widehat{\delta}, 27$ + Sagittal MRI A combination of increased posterior et al. 2010 study (level III) Controls: $n=55(22 \hat{\varnothing}, 33$ o $) \quad$ tibial plateau slope and shallow medial tibial plateau depth could be a major risk factor in anterior cruciate ligament injury susceptibility regardless of gender. Men and women present different risk factors

\begin{tabular}{|c|c|c|c|}
\hline $\begin{array}{l}\text { Simon } \\
\text { et al. } 2010\end{array}$ & $\begin{array}{l}\text { Retrospective } \\
\text { case-control } \\
\text { study (level III) }\end{array}$ & $\frac{\text { Cases: } n=27(17 \hat{\jmath}, 10 \text { q) }}{\text { Controls: } n=27(17 \hat{\jmath}, 10+)}$ & $\begin{array}{l}\text { 3D-SPGR } \\
\text { axial and } \\
\text { sagittal MRI }\end{array}$ \\
\hline $\begin{array}{l}\text { Hudek } \\
\text { et al. } 2011\end{array}$ & $\begin{array}{l}\text { Prognostic } \\
\text { study (level II) }\end{array}$ & $\begin{array}{l}\text { Cases: } n=55(24 \hat{\jmath}, 31 \text { + }) \\
\text { Controls: } n=55(24 \hat{\delta}, 31 \text { ㅇ })\end{array}$ & Sagittal MRI \\
\hline
\end{tabular}

The lateral tibial plateaus in the uninjured contralateral knees of the injured subjects had a significantly steeper posterior slope

et al. 2011 study (level II) Controls: $n=55(24 \hat{\jmath}, 31$ ㅇ) There is no obvious link between the medial or lateral posterior tibial slopes (PTS) and ACL injury. However, a greater lateral meniscus slope may indicate a greater risk of injury. The PTS can differ between the genders but the average difference is small 
Table 2 (continued)

\begin{tabular}{|c|c|c|c|c|}
\hline Author(s) & $\begin{array}{l}\text { Study design } \\
\text { (level of } \\
\text { evidence) }\end{array}$ & $N$ (patients enrolled) & MRI protocol & Conclusions \\
\hline $\begin{array}{l}\text { Khan } \\
\text { et al. } 2011\end{array}$ & $\begin{array}{l}\text { Retrospective } \\
\text { case-control } \\
\text { study (level III) }\end{array}$ & 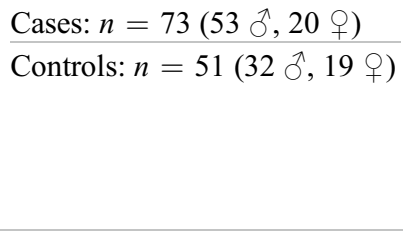 & Sagittal MRI & $\begin{array}{l}\text { Women with shallower medial tibial } \\
\text { plateau depth and men with steeper } \\
\text { lateral tibial plateau slope (LTPS) are } \\
\text { at higher risk of sustaining ACL injury. } \\
\text { Overall, steeper LTPS is a significant } \\
\text { risk factor for sustaining ACL injury }\end{array}$ \\
\hline $\begin{array}{l}\text { Terauchi } \\
\text { et al. } 2011\end{array}$ & $\begin{array}{l}\text { Cross-sectional } \\
\text { study (level III) }\end{array}$ & 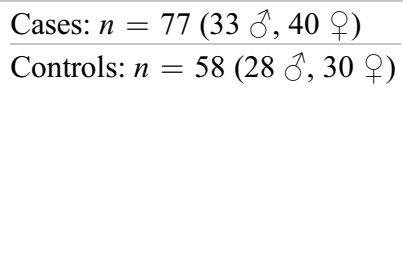 & $\begin{array}{l}\text { T2-weighted } \\
\text { sagittal MRI }\end{array}$ & $\begin{array}{l}\text { There were } 2 \text { types of large femoral } \\
\text { plateau angles: one had its origin in an } \\
\text { increasing tibial posterior slope and } \\
\text { the other resulted from hyperextension } \\
\text { of the knee. Large posterior tibial slope } \\
\text { and hyperextension are both correlated } \\
\text { with noncontact ACL injury in women }\end{array}$ \\
\hline
\end{tabular}

plateau slope (LTPS) are at higher risk of sustaining ACL injury. Overall, steeper LTPS might be considered a significant risk factor for sustaining ACL injury (Khan et al. 2011).

Besides morphologic assessment, nowadays it is possible to combine morphologic and functional assessment of the knee joint during one single MRI or CT-based examination by means of using the Porto Knee Testing Device (PKTD) (Espregueira-Mendes et al. 2012; Pereira et al. 2012). In this way one might combine the study of morphologic bony parameters with evaluation of anteroposterior and rotational laxity (Fig. 3).

CT scan is many times useful particularly in patients submitted to previous primary ACL reconstruction to study tunnel placement as well as the surrounding bony structure. By combining CT with PKTD, we simultaneously can objective measure joint parameters concerning laxity (Fig. 4).

PKTD might play a role in prevention strategies by favoring detection of risk factors and/or identifying those patients presenting higher rotational instability and who may require an ACL reconstruction technique which provides higher rotational constraint (e.g., double-bundle) (Hemmerich et al. 2011).

These data provide one further step in understanding knee kinematics, but their functional implication and the way in which they might affect ACL reconstruction are not fully achieved. ACL research demands perseverance and patience (Lubowitz and Poehling 2010). 


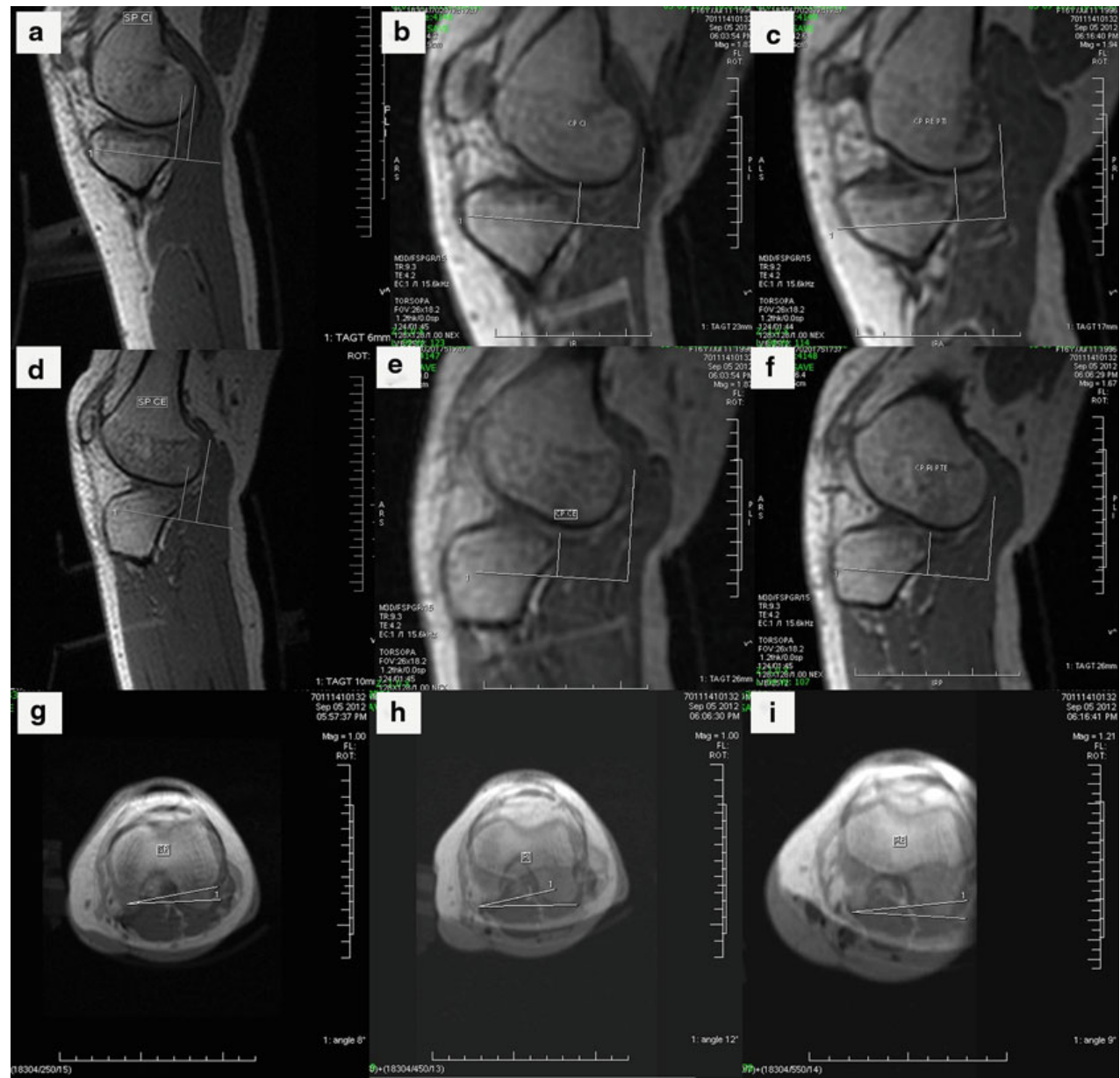

Fig. 3 Standard protocol evaluation with PKTD: Sagittal view with foot in neutral position without load application correspondent to medial (a) and lateral compartments (c). Result after load applications correspondent to medial (b) and lateral compartments (d). In this case, the differential would be respectively of 17 and $16 \mathrm{~mm}$. Image correspondent to load after maximum internal foot rotation in lateral compartment (e) and after maximum external foot rotation in medial compartment (f). Evaluation of angular and linear tibial dislocation from axial views: without load (g) and with load after internal (h) and external foot rotation (i). Evaluation confirmed global ACL insufficiency

\section{Summary}

Ideal screening methods for risk factors need to be relatively low cost, noninvasive, and simple, with minimal time requirements.

Currently there is no effective "tool" nor even straightforward guidelines for how some of the identified risk factors can be used to assist the clinician.

The relevance of bone morphology as a possible risk factor for ACL rupture has been reinforced. Besides all the knowledge achieved by research using expensive technological devices such as robotics, gait analysis laboratories or navigation keeps being far from routine use aiming for detection of risk factors. New technological options such as the iPad app promise to provide significant progress in standardization and quantification of clinical examinations. Moreover, such 

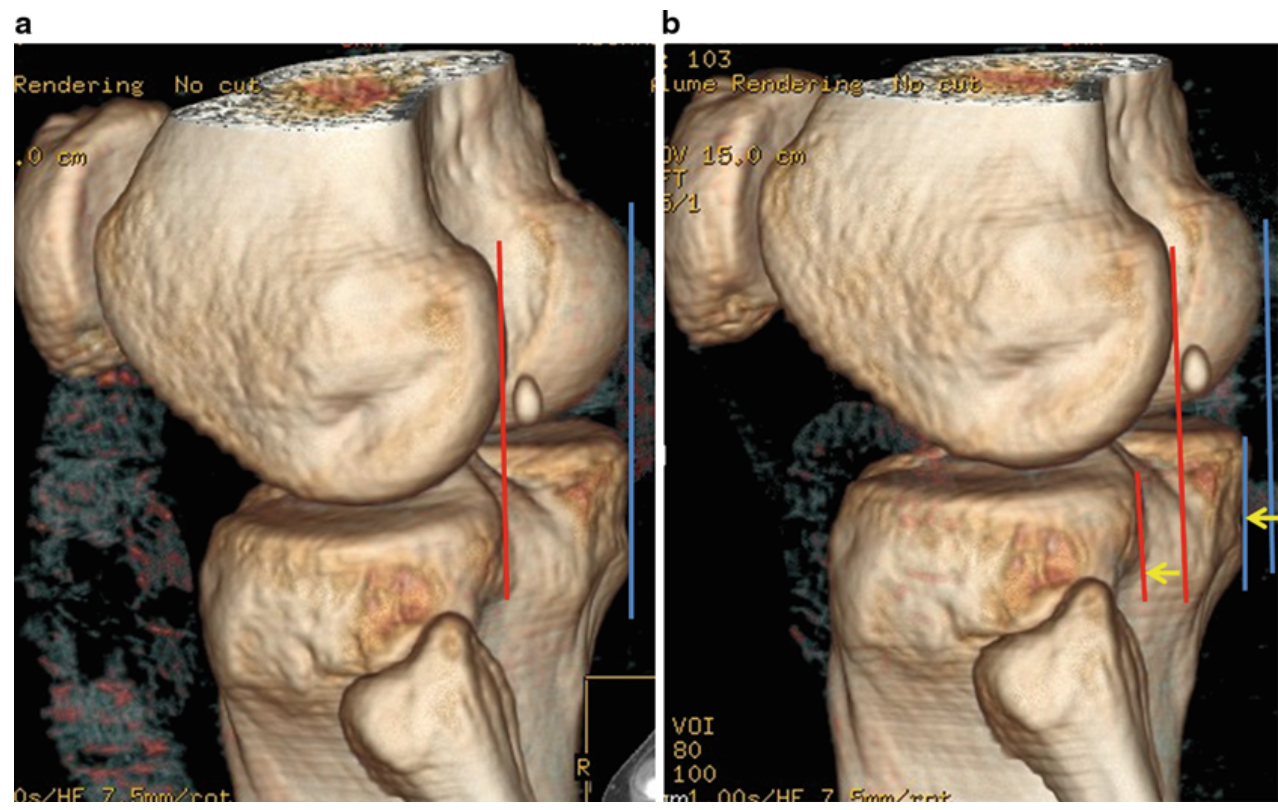

Fig. 4 CT 3D imaging reconstruction of PKTD examination. Initial position without load application (a). After load application notice yellow arrows representing anterior tibial displacement (b)

devices could combine, in future, consideration of clinical and imaging findings in a user-friendly method while combining multiple factors in more complex algorithms. Dynamic MRI with PKTD has brought novel insights to more detailed anatomic and functional evaluation.

More important than "isolated" research lines, it would be necessary to combine all up-to-date insights and modern knowledge in a single and practical screening method.

\section{Cross-References}

- ACL Augmentation in Partial Ruptures

- ACL Injuries and Surgery Current Evidence and Modern Development

$\checkmark$ ACL Injuries in Children

- Partial ACL Ruptures: Knee Laxity Measurements and Pivot Shift

\section{References}

Alizadeh A, Kiavash V (2008) Mean intercondylar notch width index in cases with and without anterior cruciate ligament tears. Iran J Radiol 5:205-208

Al-Saeed O, Brown M, Athyal R, Sheikh M (2013) Association of femoral intercondylar notch morphology, width index and the risk of anterior cruciate ligament injury. Knee Surg Sports Traumatol Arthrosc 21:678-682

Arendt EA, Brown GA (2012) Non-contact ACL injury: can anatomic factors be used in screening at-risk athletes? Commentary on an article by Christopher J. Wahl, MD, et al.: "An association of 
lateral knee sagittal anatomic factors with non-contact ACL injury: sex or geometry?”. J Bone Joint Surg Am 94:e20

Balasch H, Schiller M, Friebel H, Hoffmann F (1999) Evaluation of anterior knee joint instability with the Rolimeter. A test in comparison with manual assessment and measuring with the KT-1000 arthrometer. Knee Surg Sports Traumatol Arthrosc 7:204-208

Benvenuti JF, Vallotton JA, Meystre JL, Leyvraz PF (1998) Objective assessment of the anterior tibial translation in Lachman test position. Comparison between three types of measurement. Knee Surg Sports Traumatol Arthrosc 6:215-219

Bisson LJ, Gurske-DePerio J (2010) Axial and sagittal knee geometry as a risk factor for noncontact anterior cruciate ligament tear: a case-control study. Arthroscopy 26:901-906

Boniface RJ, Fu FH, Ilkhanipour K (1986) Objective anterior cruciate ligament testing. Orthopedics 9:391-393

Boyer P, Djian P, Christel P, Paoletti X, Degeorges R (2004) Reliability of the KT-1000 arthrometer (Medmetric) for measuring anterior knee laxity: comparison with Telos in 147 knees. Rev Chir Orthop Reparatrice Appar Mot 90:757-764

Branch TP, Browne JE, Campbell JD, Siebold R, Freedberg HI, Arendt EA et al (2010a) Rotational laxity greater in patients with contralateral anterior cruciate ligament injury than healthy volunteers. Knee Surg Sports Traumatol Arthrosc 18:1379-1384

Branch TP, Mayr HO, Browne JE, Campbell JC, Stoehr A, Jacobs CA (2010b) Instrumented examination of anterior cruciate ligament injuries: minimizing flaws of the manual clinical examination. Arthroscopy 26:997-1004

Chadwick CC, Rogowski J, Joyce BT (2008) The economics of anterior cruciate ligament reconstruction. In: Prodromos C, Brown C, F FH, Georgoulis AD, Gobbi A, Howell SM (eds) The anterior cruciate ligament: reconstruction and basic science. Saunders Elsevier, Philadelphia, pp 79-83

Citak M, Suero EM, Rozell JC, Bosscher MR, Kuestermeyer J, Pearle AD (2011) A mechanized and standardized pivot shifter: technical description and first evaluation. Knee Surg Sports Traumatol Arthrosc 19:707-711

Daniel DM, Stone ML, Sachs R, Malcom L (1985) Instrumented measurement of anterior knee laxity in patients with acute anterior cruciate ligament disruption. Am J Sports Med 13:401-407

Dejour H, Bonnin M (1994) Tibial translation after anterior cruciate ligament rupture. Two radiological tests compared. J Bone Joint Surg (Br) 76:745-749

Espregueira-Mendes J, Pereira H, Sevivas N, Passos C, Vasconcelos JC, Monteiro A et al (2012) Assessment of rotatory laxity in anterior cruciate ligament-deficient knees using magnetic resonance imaging with Porto-knee testing device. Knee Surg Sports Traumatol Arthrosc $20: 671-678$

Feucht MJ, Mauro CS, Brucker PU, Imhoff AB, Hinterwimmer S (2013) The role of the tibial slope in sustaining and treating anterior cruciate ligament injuries. Knee Surg Sports Traumatol Arthrosc 21:134-145

Georgoulis AD, Ristanis S, Chouliaras V, Moraiti C, Stergiou N (2007) Tibial rotation is not restored after ACL reconstruction with a hamstring graft. Clin Orthop Relat Res 454:89-94

Griffin LY, Agel J, Albohm MJ, Arendt EA, Dick RW, Garrett WE et al (2000) Noncontact anterior cruciate ligament injuries: risk factors and prevention strategies. J Am Acad Orthop Surg $8: 141-150$

Hashemi J, Chandrashekar N, Mansouri H, Gill B, Slauterbeck JR, Schutt RC Jr et al (2010) Shallow medial tibial plateau and steep medial and lateral tibial slopes: new risk factors for anterior cruciate ligament injuries. Am J Sports Med 38:54-62 
Hemmerich A, van der Merwe W, Batterham M, Vaughan CL (2011) Knee rotational laxity in a randomized comparison of single- versus double-bundle anterior cruciate ligament reconstruction. Am J Sports Med 39:48-56

Highgenboten CL, Jackson A, Meske NB (1989) Genucom, KT-1000, and Stryker knee laxity measuring device comparisons. Am J Sports Med 17:743-746

Hoshino Y, Araujo P, Ahlden M, Samuelsson K, Muller B, Hofbauer M et al (2013) Quantitative evaluation of the pivot shift by image analysis using the iPad. Knee Surg Sports Traumatol Arthrosc 21:975-980

Hudek R, Fuchs B, Regenfelder F, Koch PP (2011) Is noncontact ACL injury associated with the posterior tibial and meniscal slope? Clin Orthop Relat Res 469:2377-2384

Isberg J, Faxen E, Brandsson S, Eriksson BI, Karrholm J, Karlsson J (2006) KT-1000 records smaller side-to-side differences than radiostereometric analysis before and after an ACL reconstruction. Knee Surg Sports Traumatol Arthrosc 14:529-535

Jardin C, Chantelot C, Migaud H, Gougeon F, Debroucker MJ, Duquennoy A (1999) Reliability of the KT-1000 arthrometer in measuring anterior laxity of the knee: comparative analysis with Telos of 48 reconstructions of the anterior cruciate ligament and intra- and interobserver reproducibility. Rev Chir Orthop Reparatrice Appar Mot 85:698-707

Jonsson H, Elmqvist LG, Karrholm J, Fugl-Meyer A (1992) Lengthening of anterior cruciate ligament graft. Roentgen stereophotogrammetry of 32 cases 2 years after repair. Acta Orthop Scand 63:587-592

Jung TM, Reinhardt C, Scheffler SU, Weiler A (2006) Stress radiography to measure posterior cruciate ligament insufficiency: a comparison of five different techniques. Knee Surg Sports Traumatol Arthrosc 14:1116-1121

Katz JW, Fingeroth RJ (1986) The diagnostic accuracy of ruptures of the anterior cruciate ligament comparing the Lachman test, the anterior drawer sign, and the pivot shift test in acute and chronic knee injuries. Am J Sports Med 14:88-91

Khan MS, Seon JK, Song EK (2011) Risk factors for anterior cruciate ligament injury: assessment of tibial plateau anatomic variables on conventional MRI using a new combined method. Int Orthop $35: 1251-1256$

Kvist J (2004) Sagittal plane translation during level walking in poor-functioning and wellfunctioning patients with anterior cruciate ligament deficiency. Am J Sports Med 32:1250-1255

Lob T, Verheyden AP, Josten Ch, (2006) The function of the ACL measured in an vertical opened MRI (0.5 Tesla). In: 12th F S ESSKA congress, Innsbruck

Lubowitz JH, Poehling GG (2010) Understanding ACL research requires patience and persistence. Arthroscopy 26:869-871

Mayr HO, Hoell A, Bernstein A, Hube R, Zeiler C, Kalteis T et al (2011) Validation of a measurement device for instrumented quantification of anterior translation and rotational assessment of the knee. Arthroscopy 27:1096-1104

Menetrey J, Duthon VB, Laumonier T, Fritschy D (2008) "Biological failure" of the anterior cruciate ligament graft. Knee Surg Sports Traumatol Arthrosc 16:224-231

Miljko M, Grle M, Kozul S, Kolobaric M, Djak I (2012) Intercondylar notch width and inner angle of lateral femoral condyle as the risk factors for anterior cruciate ligament injury in female handball players in Herzegovina. Coll Antropol 36:195-200

Musahl V, Voos J, O’Loughlin PF, Stueber V, Kendoff D, Pearle AD (2010) Mechanized pivot shift test achieves greater accuracy than manual pivot shift test. Knee Surg Sports Traumatol Arthrosc $18: 1208-1213$ 
Myer GD, Ford KR, Hewett TE (2011) New method to identify athletes at high risk of ACL injury using clinic-based measurements and freeware computer analysis. Br J Sports Med 45:238-244

Myrer JW, Schulthies SS, Fellingham GW (1996) Relative and absolute reliability of the KT-2000 arthrometer for uninjured knees. Am J Sports Med 24:104-108

Oliver JH, Coughlin LP (1987) Objective knee evaluation using the Genucom Knee Analysis System. Clinical implications. Am J Sports Med 15:571-578

Owings MF, Kozak LJ (1998) Ambulatory and inpatient procedures in the United States, 1996. Vital Health Stat 13:1-119

Park HS, Wilson NA, Zhang LQ (2008) Gender differences in passive knee biomechanical properties in tibial rotation. J Orthop Res 26:937-944

Pereira H, Sevivas N, Pereira R, Monteiro A, Oliveira JM, Reis RL et al (2012) New tools for diagnosis, assessment of surgical outcome and follow-up. In: Hernández J, Monllau JC (eds) Lesiones Ligamentosas de La Rodilla. Marge Books, Barcelona, pp 185-194

Pereira H, Silva-Correia J, Yan LP, Oliveira A, Oliveira JM, Espregueira-Mendes J et al (2013) Radiographic method to determine risk factors for ACL rupture in athletes based in bone morphology. In: French Arthroscopy Society meeting, Bordeaux

Prins M (2006) The Lachman test is the most sensitive and the pivot shift the most specific test for the diagnosis of ACL rupture. Aust J Physiother 52:66

Robert H, Nouveau S, Gageot S, Gagniere B (2009) A new knee arthrometer, the GNRB: experience in ACL complete and partial tears. Orthop Traumatol Surg Res 95:171-176

Schulz MS, Russe K, Lampakis G, Strobel MJ (2005) Reliability of stress radiography for evaluation of posterior knee laxity. Am J Sports Med 33:502-506

Selvik G (1989) Roentgen stereophotogrammetry. A method for the study of the kinematics of the skeletal system. Acta Orthop Scand Suppl 232:1-51

Simon RA, Everhart JS, Nagaraja HN, Chaudhari AM (2010) A case-control study of anterior cruciate ligament volume, tibial plateau slopes and intercondylar notch dimensions in ACL-injured knees. J Biomech 43:1702-1707

Smith HC, Vacek P, Johnson RJ, Slauterbeck JR, Hashemi J, Shultz S et al (2012a) Risk factors for anterior cruciate ligament injury: a review of the literature-part 2: hormonal, genetic, cognitive function, previous injury, and extrinsic risk factors. Sports Health 4:155-161

Smith HC, Vacek P, Johnson RJ, Slauterbeck JR, Hashemi J, Shultz S et al (2012b) Risk factors for anterior cruciate ligament injury: a review of the literature - part 1: neuromuscular and anatomic risk. Sports Health 4:69-78

Sorensen OG, Larsen K, Jakobsen BW, Kold S, Hansen TB, Lind M et al (2011) The combination of radiostereometric analysis and the telos stress device results in poor precision for knee laxity measurements after anterior cruciate ligament reconstruction. Knee Surg Sports Traumatol Arthrosc 19:355-362

Staubli HU, Noesberger B, Jakob RP (1992) Stress radiography of the knee. Cruciate ligament function studied in 138 patients. Acta Orthop Scand Suppl 249:1-27

Stijak L, Herzog RF, Schai P (2008) Is there an influence of the tibial slope of the lateral condyle on the ACL lesion? A case-control study. Knee Surg Sports Traumatol Arthrosc 16:112-117

Stijak L, Malis M, Maksimovic R, Aksic M, Filipovic B (2012) The influence of the morphometric parameters of the intercondylar notch on rupture of the anterior cruciate ligament. Vojnosanit Pregl 69:576-580

Sutton KM, Bullock JM (2013) Anterior cruciate ligament rupture: differences between males and females. J Am Acad Orthop Surg 21:41-50 
Sward P, Kostogiannis I, Roos H (2010) Risk factors for a contralateral anterior cruciate ligament injury. Knee Surg Sports Traumatol Arthrosc 18:277-291

Tashman S, Kolowich P, Collon D, Anderson K, Anderst W (2007) Dynamic function of the ACL-reconstructed knee during running. Clin Orthop Relat Res 454:66-73

Terauchi M, Hatayama K, Yanagisawa S, Saito K, Takagishi K (2011) Sagittal alignment of the knee and its relationship to noncontact anterior cruciate ligament injuries. Am J Sports Med 39:1090-1094

Tsai AG, Musahl V, Steckel H, Bell KM, Zantop T, Irrgang JJ et al (2008) Rotational knee laxity: reliability of a simple measurement device in vivo. BMC Musculoskelet Disord 9:35

Vyas S, van Eck CF, Vyas N, Fu FH, Otsuka NY (2011) Increased medial tibial slope in teenage pediatric population with open physes and anterior cruciate ligament injuries. Knee Surg Sports Traumatol Arthrosc 19:372-377

Woo SLY, Fisher MB (2009) Evaluation of knee stability with use of a robotic system. J Bone Joint Surg (Am) 91:78-84

Wordeman SC, Quatman CE, Kaeding CC, Hewett TE (2012) In vivo evidence for tibial plateau slope as a risk factor for anterior cruciate ligament injury: a systematic review and meta-analysis. Am J Sports Med 40:1673-1681 


\section{Index Terms:}

Anterior cruciate ligament (ACL) 1

iPad application 3

KT-1000 2

Lachman test 3

Pivot-shift 4

PKTD 5

Robotics 9 